\title{
The Criteria for Selecting Strategic Execution Software for Higher Education
}

\author{
Dr. Abdulfattah Mashat \\ President, \\ Jeddah University, Jeddah \\ Kingdom of Saudi Arabia \\ asmashat@kau.edu.sa
}

\author{
Dr. Ibrahim Al Bidewi \\ Strategic Planning Dept, \\ King Abdulaziz \\ University, Jeddah, \\ Saudi Arabia \\ ialbidewi@kau.edu.sa
}

\author{
Dr. Usman Ali Khan \\ Dept. of IS-FCIT, \\ King Abdulaziz \\ University, Jeddah, \\ Saudi Arabia \\ ukhan@kau.edu.sa
}

\author{
Dr. M. Khursheed Akhtar \\ Strategic Planning Dept, \\ King Abdulaziz University, \\ Jeddah, Saudi Arabia \\ mkakhtar@kau.edu.sa
}

\begin{abstract}
Almost two decades, the educational institutions using tables and sheets to represent their strategic planning and programs for execution and reporting purposes. Now, this is age of Information Technology, the programs and projects are better represent and easily manage at the finger tips access. In this paper, we mainly focus on selection of suitable strategic execution software using specific criteria which will help us to develop, maintain and monitor our strategic programs and projects for higher education.
\end{abstract}

\section{Keywords}

Strategic Planning, Execution, Reporting, Criteria, programs and Projects.

\section{INTRODUCTION}

The selection of significant software application which serves the specific purpose is a very tedious and cumbersome job. But, it is our dire necessity to select appropriate and relevant software because without suitable software you could not manage your tasks at finger tips access. There are many organizations which have their own in-house built software, but they do not suffice their entire requirements. Only they serve 25 percentages of their organizational needs. The initial process of selecting software is to classify our requirements that best fit in our organization's needs and purpose as required by senior executives those are responsible for the same departments and who has information

\begin{abstract}
technology background or having prior IT knowledge and having strategic vision as well. A team is should be assembled or assigned which including a senior-level executive to direct its activities and keep its focus on those specific goals and objectives. The Department managers and an IT staff, who must make the software, work smoothly. Otherwise, he may suffer the consequences of this software failure. So, it is better to chosen very carefully using their IT knowledge and better judgment. It is also advisable to include some departmental heads to join the demo sessions given by the vendors and ask their feedback time to time. It is also necessary to use IT staff to investigate regarding required functionalities available or not as per vendor's commitment. It means that they must assess and verify the software parameters to ensure that the technology and functionality of the software may satisfy the organizational strategic and tactical plans forward without quickly becoming obsolete.
\end{abstract}

\section{SOFTWARE REQUIREMENT CRITERIA}

Before selecting the software companies, we prepare our case study with some functional criteria for selecting required tool. We have prepare a list of requirements where we listed our software requirement purpose, users categories, license year, needs of organization, reporting facilities, data migration and few more options which we entail during the development of our third year strategic plan. The following are the basic requirements of strategic executions software listed below, which will help us to find the correct and appropriate strategic execution software tool.

Table 1: List of KPIs require for most of the academic institutions

\begin{tabular}{|c|c|c|c|}
\hline \multicolumn{2}{|r|}{ For Values (10 to 15 approx.) } & \multicolumn{2}{|r|}{ For Strategic Objectives (20 to 25 approx.) } \\
\hline a. & Piety & a. & Effective Teaching and Learning \\
\hline b. & Kindness & b. & Graduate Studies and Scientific Research \\
\hline c. & Cooperation & c. & Social Responsibility \\
\hline d. & Patriotism & d. & Innovation and Leadership and Development \\
\hline e. & Excellence & & Infrastructure \\
\hline f. & Innovation & & Information Technology \\
\hline g. & Sustainability & & Investment \\
\hline
\end{tabular}




\section{The Criteria for Selecting Strategic Execution Software for Higher Education}

\section{SOFTWARE SELECTION METHODOLOGY}

For selection methodology, we use a capeterra.com as a search engine after putting the criteria as Business Performance Management. There are more than 2,000 plus software available related to the Top Business Performance Management software Product criteria using website www.capeterra.com.

Among these top Business Performance management software companies, we have selected more than 30 companies considering two majors points that the software should be web based and best installed in the server for safety and security purpose. As we know that application installed in server is more secured than installed applications in other workstations. The second most important criteria have been mentioned in Chapter V.

\section{SOFTWARE SELECTION CHECKLIST}

It is quite difficult and cumbersome to identify and select a tool that is appropriate for a particular project. There are many deliberations and considerations that need to be dealt with while selecting a software tool. In the beginning of selection to select an important software tool, it is better to create a check list of functionalities considering cost, user friendly interface, easy to use, technical support facilities from vendor side, easy installation, localization and above all taking into account that the tool should be menu driven customized application. There is different check list selection approach from different organizations.

For the checklist selection (Table 2), we create exults by marking a checkmark using data columns against various check points as well as missing functionalities on the checklist. A checkmark is used as a Yes column against an item indicates that the functionalities available in this toll are true. A checkmark in the not available (N/A) column against an item indicates that the functionalities are not applicable. The checklist can be customized and add an additional columns like comments, may be added which could provide useful assistance during further analysis.

Table 2: A sample of Software Selection Checklist

\begin{tabular}{|c|c|c|c|}
\hline \multirow[t]{2}{*}{ S.No } & \multirow[t]{2}{*}{ Functionality Check Point Criteria } & \multicolumn{2}{|c|}{$\begin{array}{l}\text { Check Mark }(\sqrt{ }) \text { the } \\
\text { Appropriate Column }\end{array}$} \\
\hline & & Yes & N/A \\
\hline 01 & Whether the price of the tool fit in the department or institution budget? & & \\
\hline 02 & $\begin{array}{l}\text { Whether the tool meets the requirements of the institution testing } \\
\text { methodology? }\end{array}$ & & \\
\hline 03 & $\begin{array}{l}\text { Whether training, classes, user guides, or other forms of instruction are } \\
\text { available and necessary for using this tool? }\end{array}$ & & \\
\hline 04 & $\begin{array}{l}\text { Whether the tool will work effectively on the computer system, currently in } \\
\text { place? }\end{array}$ & & \\
\hline 05 & Whether more memory, faster processors going to be needed? & & \\
\hline 06 & Whether the tool itself is easy to use and a user-friendly interface? & & \\
\hline 07 & $\begin{array}{l}\text { Whether the tool is prone to user error and physically capable of testing your } \\
\text { application? }\end{array}$ & & \\
\hline 08 & $\begin{array}{l}\text { Whether the tool can run for long periods of time without crashing, or is the } \\
\text { tool itself full of bugs and can handle full project testing? }\end{array}$ & & \\
\hline 09 & $\begin{array}{l}\text { Whether you have talked to the customers who currently or previously have } \\
\text { used the tool. Did it meet their needs? }\end{array}$ & & \\
\hline 10 & $\begin{array}{l}\text { How similar were their testing needs to yours and how well did the tool } \\
\text { perform? }\end{array}$ & & \\
\hline 11 & $\begin{array}{l}\text { Whether you are trying to select a tool that is advanced enough so the costs of } \\
\text { upgrading is minimum? }\end{array}$ & & \\
\hline 12 & Is it easy menu base tool that can be picked up quickly? & & \\
\hline 13 & Whether any of the team members already have experience of using this tool? & & \\
\hline
\end{tabular}

\section{SOFTWARE CRITERIA}

For the selection of a software tool or computer application, it is always obligatory to check that the selected tool meets the requirements or not. In this perspective, we have selected some important functionality which we describe in brief to know their usefulness. 
- Ad Hoc Analysis

- Ad Hoc Reports

- Balanced Scorecards

- $\quad$ Budgeting and Forecasting

- Consolidation / roll-up

- Dashboard

- Qualitative Analysis

- Key Performance Indicators

- Quantitative analysis

- $\quad$ Strategic Planning
- Workflow Management

- Performance Management

- Other Functions

\section{LIST OF SOFTWARE COMPANIES}

During the selection of software companies, we prepare a comprehensive list of more than 30 companies which is forerunner in providing solution for strategic software execution and which satisfies our specific requirements for required functionalities.

Table 3: List of Strategic Software Companies

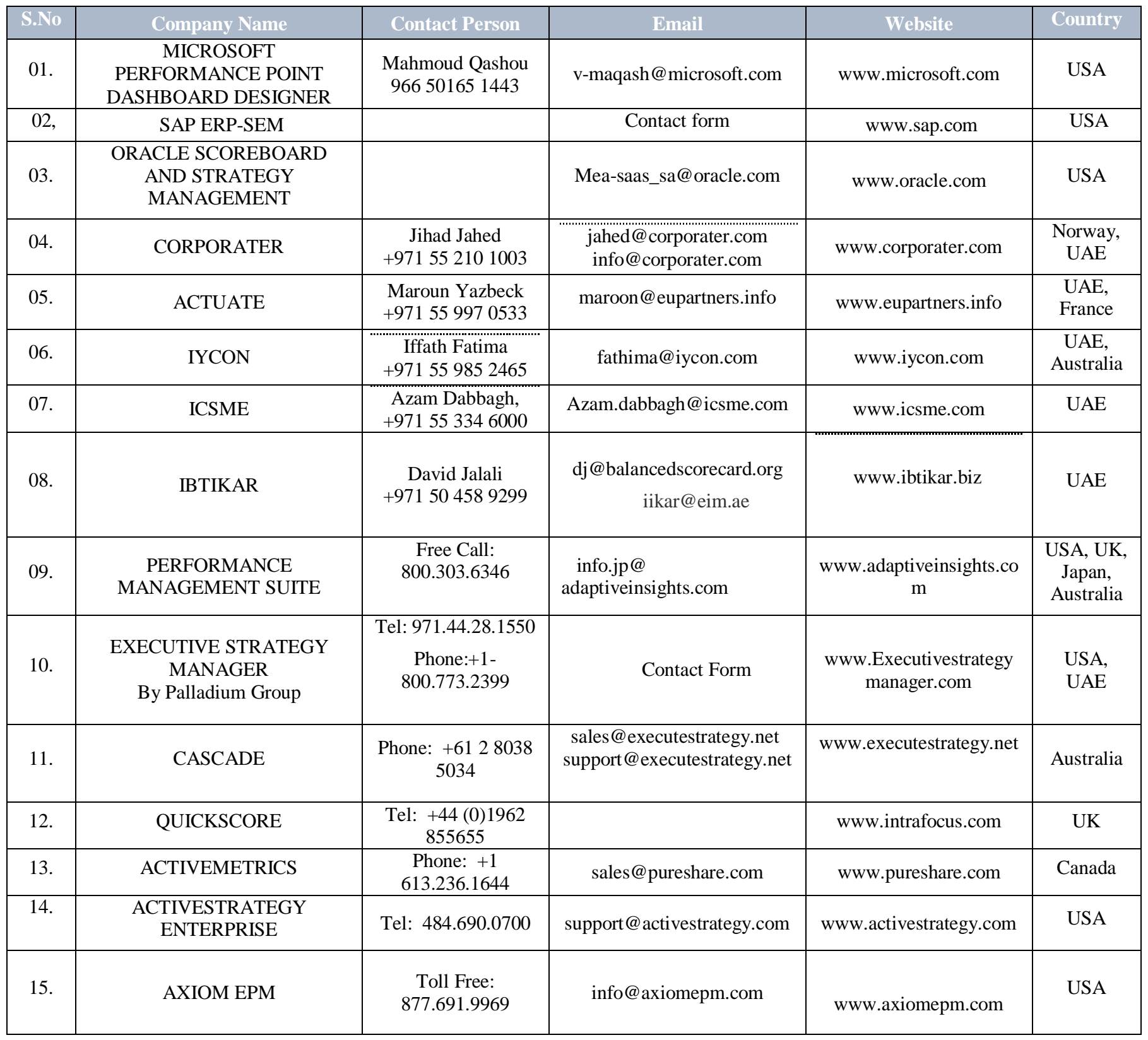


The Criteria for Selecting Strategic Execution Software for Higher Education

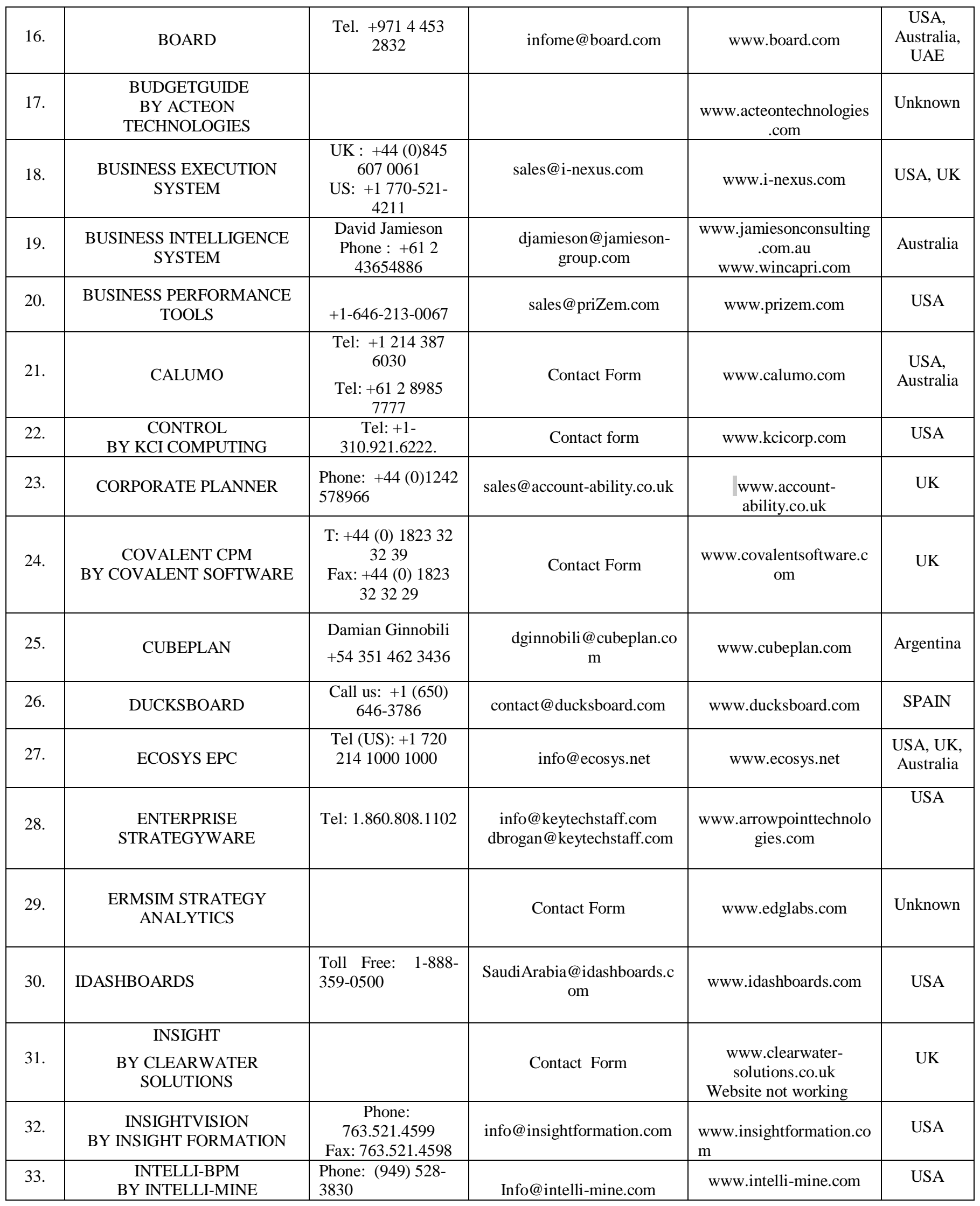




\section{PICTORIAL REPRESENTATION OF FUNCTIONALITIES OF SOFTWARE COMPANIES}

As per the functionality and important use, we categorize the different criteria mark them. We have provided suitable
Weightage point for different 14 criteria from 5 to 20 points totaling 100 Marks to see which company score highest marks and then we may short list at least 5 companied and ask them to give us life demo at the earliest.

Table 4: List of Software selection Criteria

\begin{tabular}{|c|c|c|c|c|c|c|c|c|c|c|c|c|c|c|c|}
\hline S.No & COMPANY & 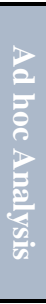 & 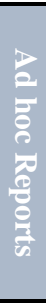 & 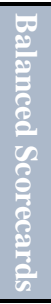 & 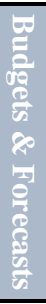 & 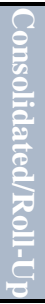 & 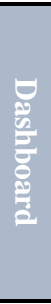 & 즙 & 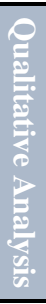 & 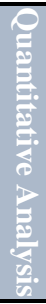 & 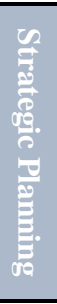 & 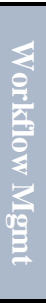 & 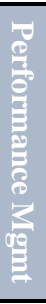 & 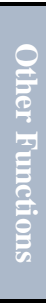 & 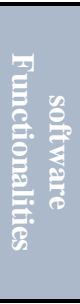 \\
\hline 1 & SAP ERP-SEM & & 5 & 15 & 5 & 5 & 10 & 20 & 5 & 5 & 10 & 5 & 5 & 5 & 95 \\
\hline 2 & AXIOM EPM & 5 & 5 & 15 & 5 & 5 & 10 & 20 & 5 & 5 & 10 & 5 & & & 90 \\
\hline 3 & CUBEPLAN & 5 & 5 & 15 & 5 & 5 & 10 & 20 & 5 & 5 & 10 & 5 & & & 90 \\
\hline 4 & ECOSYS EPC & 5 & 5 & 15 & 5 & 5 & 10 & 20 & 5 & 5 & 10 & 5 & & & 90 \\
\hline 5 & IDASHBOARDS & 5 & 5 & 15 & 5 & & 10 & 20 & 5 & 5 & 10 & 5 & & 5 & 90 \\
\hline 6 & $\begin{array}{l}\text { EXECUTIVE } \\
\text { STRATEGY } \\
\text { MANAGER } \\
\end{array}$ & & 5 & 15 & 5 & 5 & 10 & 20 & 5 & 5 & 10 & 5 & & & 85 \\
\hline 7 & QUICKSCORE & 5 & 5 & 15 & 5 & 5 & 10 & 20 & 5 & 5 & 10 & & & & 85 \\
\hline 8 & INSIGHT SOLUTIONS & 5 & 5 & 15 & & 5 & 10 & 20 & 5 & 5 & 10 & 5 & & & 85 \\
\hline 9 & $\begin{array}{l}\text { ORACLE } \\
\text { SCOREBOARD }\end{array}$ & & 5 & 15 & 5 & 5 & 10 & 20 & & & 5 & 5 & 5 & 5 & 80 \\
\hline 10 & BOARD & 5 & 5 & & 5 & 5 & 10 & 20 & 5 & 5 & 10 & 5 & & & 75 \\
\hline 11 & CALUMO & 5 & 5 & & 5 & 5 & 10 & 20 & 5 & 5 & 10 & 5 & & & 75 \\
\hline 12 & $\begin{array}{l}\text { CORPORATE } \\
\text { PLANNER }\end{array}$ & 5 & 5 & & 5 & 5 & 10 & 20 & 5 & 5 & 10 & & & & 70 \\
\hline 13 & COVALENT CPM & 5 & 5 & 15 & & & 10 & 20 & & & 10 & 5 & & & 70 \\
\hline 14 & INTELLI-BPM & 5 & 5 & & & 5 & 10 & 20 & 5 & 5 & 10 & 5 & & & 70 \\
\hline 15 & QPR SOFTWARE & 5 & 5 & & & 5 & 10 & 20 & 5 & 5 & 10 & & & & 65 \\
\hline 16 & IYCON & & 5 & & 5 & & & 20 & 5 & 5 & 10 & 5 & 5 & 5 & 65 \\
\hline 17 & ACTIVEMETRICS & 5 & 5 & & & 5 & 10 & 20 & 5 & 5 & 10 & & & & 65 \\
\hline 18 & $\begin{array}{l}\text { CONTROL BY } \\
\text { CO. }\end{array}$ & 5 & 5 & & 5 & 5 & & 20 & 5 & 5 & 10 & 5 & & & 65 \\
\hline 19 & $\begin{array}{l}\text { ERMSIM STRATEGY } \\
\text { ANALYTICS }\end{array}$ & 5 & & 15 & & & & 20 & 5 & 5 & 10 & 5 & & & 65 \\
\hline 20 & $\begin{array}{l}\text { ENTERPRISE } \\
\text { STRATEGYWARE }\end{array}$ & & & & 5 & 5 & 10 & 20 & 5 & 5 & 10 & & & & 60 \\
\hline 21 & $\begin{array}{l}\text { ACTIVESTRATEGY } \\
\text { ENTERPRISE }\end{array}$ & & 5 & & & 5 & 10 & 20 & & & 10 & 5 & & & 55 \\
\hline 22 & $\begin{array}{l}\text { BUSINESS } \\
\text { INTELLIGENCE } \\
\text { SYSTEM } \\
\end{array}$ & 5 & 5 & & 5 & & 10 & 20 & 5 & 5 & & & & & 55 \\
\hline 23 & $\begin{array}{l}\text { BUSINESS } \\
\text { PERFORMANCE } \\
\text { TOOLS }\end{array}$ & 5 & 5 & & 5 & & & 20 & 5 & 5 & 10 & & & & 55 \\
\hline 24 & DUCKSBOARD & 5 & 5 & & & & 10 & 20 & & 5 & 10 & & & & 55 \\
\hline 25 & CORPORATER & & & 15 & 5 & 5 & 10 & & & & 10 & 5 & & & 50 \\
\hline 26 & IBTIKAR & & & 15 & & & 10 & & 5 & 5 & 10 & & & 5 & 50 \\
\hline 27 & CASCADE & & & 15 & & & 10 & & & & 10 & 5 & 5 & 5 & 50 \\
\hline 28 & $\begin{array}{l}\text { BUDGETGUIDE } \\
\text { ACTEON TECH }\end{array}$ & 5 & 5 & & 5 & 5 & 10 & & & 5 & 10 & 5 & & & 50 \\
\hline
\end{tabular}




\begin{tabular}{|c|c|c|c|c|c|c|c|c|c|c|c|c|}
\hline 29 & INSIGHTVISION & 5 & 5 & & 20 & 5 & 5 & 10 & & & & 50 \\
\hline 30 & ICSME & & & 5 & & 5 & 5 & 10 & 5 & & 5 & 35 \\
\hline 31 & $\begin{array}{l}\text { PERFORMANCE } \\
\text { MANAGEMENT } \\
\text { SUITE }\end{array}$ & 5 & 5 & 5 & & & & 10 & 5 & 5 & & 35 \\
\hline 32 & ACTUATE & & & 5 & & & & 10 & 5 & 5 & 5 & 30 \\
\hline 33 & $\begin{array}{l}\text { BUSINESS } \\
\text { EXECUTION SYSTEM }\end{array}$ & & & & & & & 10 & 5 & & & 15 \\
\hline 34 & $\begin{array}{l}\text { MICROSOFT } \\
\text { PERFORMANCE } \\
\text { POINT SCOREBAORD } \\
\text { DESIGNER }\end{array}$ & & & & & & & & & & & $\mathbf{0}$ \\
\hline
\end{tabular}

\section{SOME GRAPHICAL REPRESENTATION OF CRITERIA POINTS}

This is the graphical representation of criteria point showing the strength of the executive strategic software by creating bar chart (fig. 1) and also the line chart bar and wheel bar chart in fig. 2 and 3 respectively.

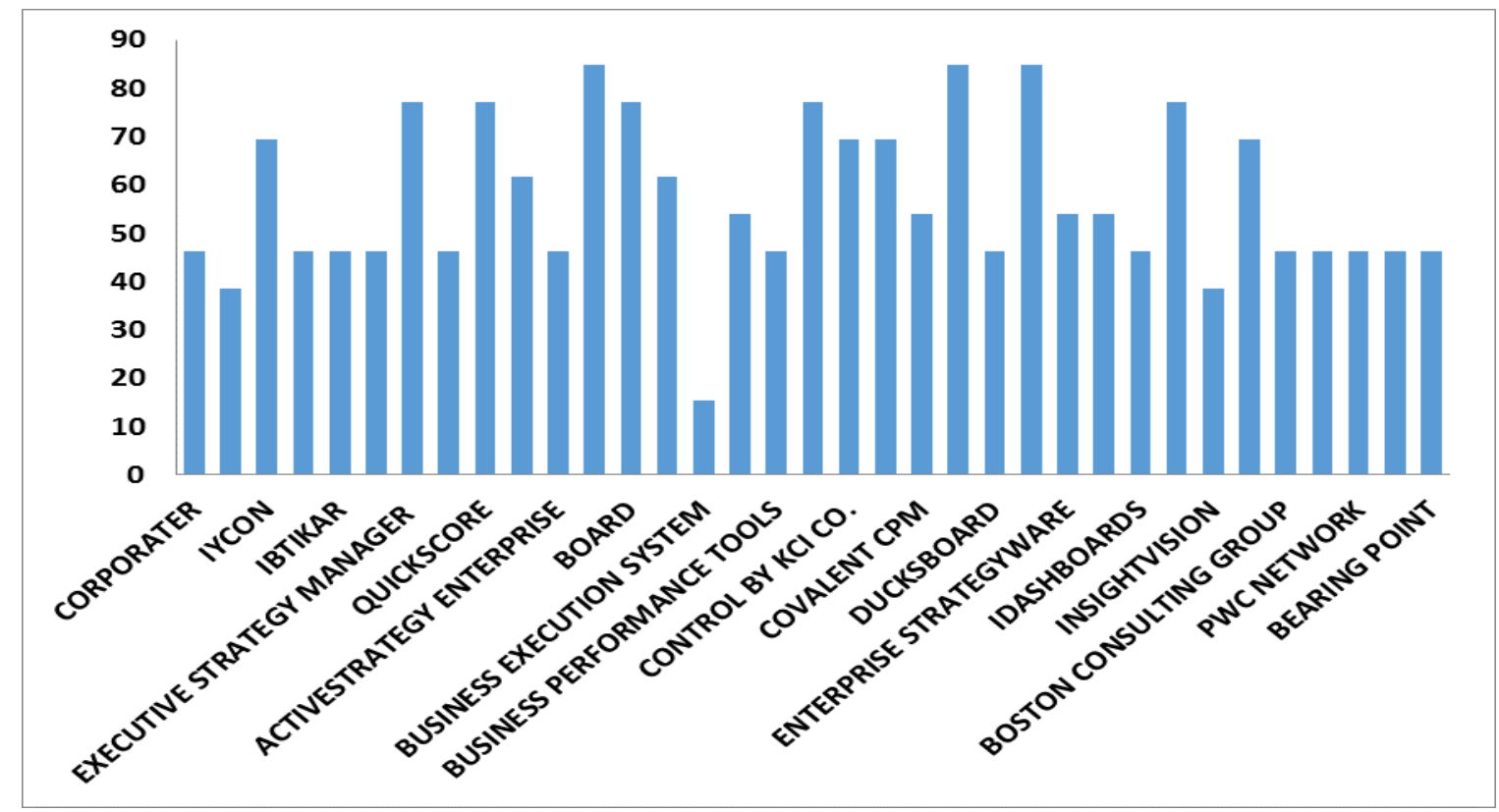

Figure 1: Graphical representation of Criteria Points 


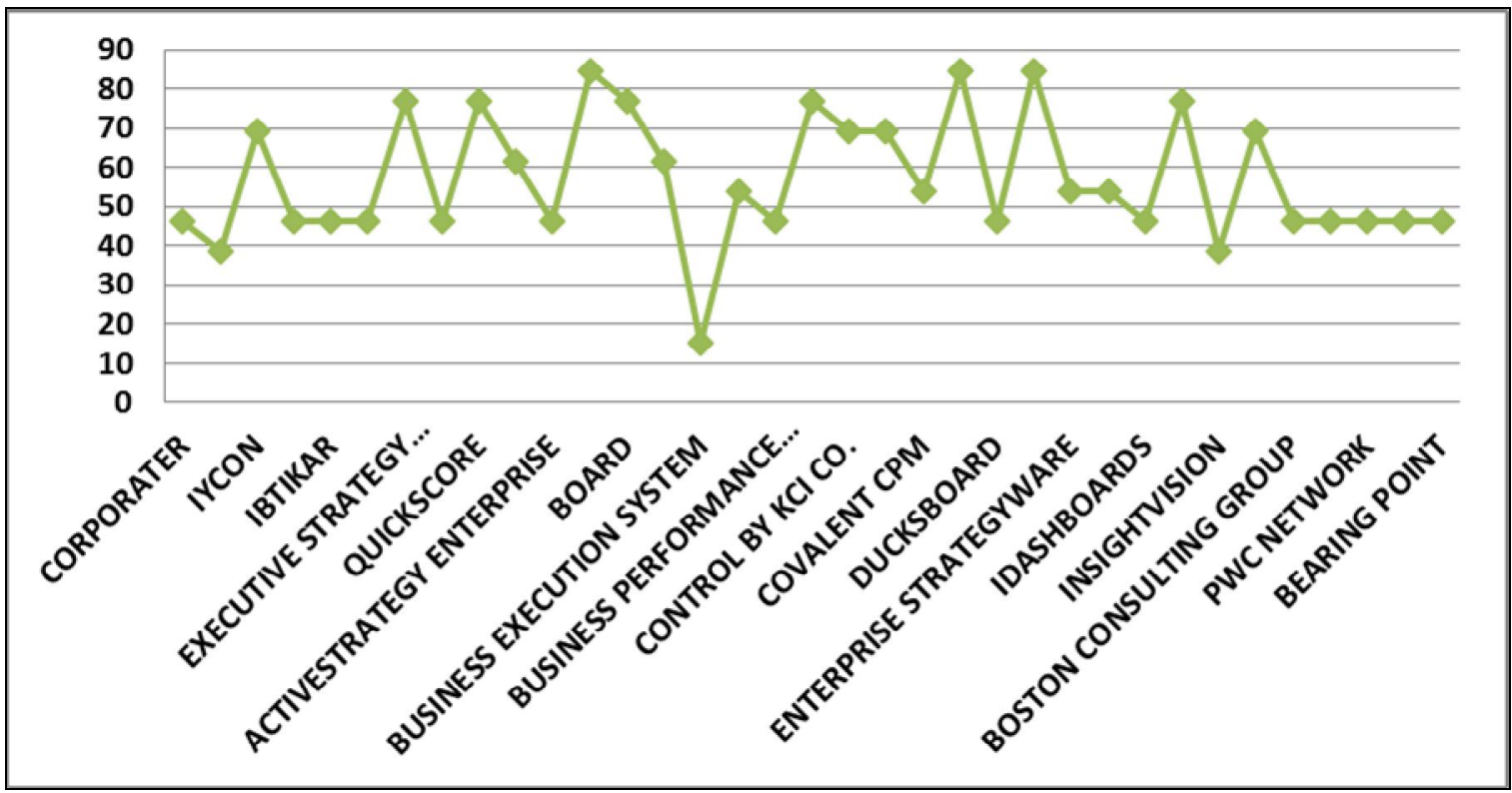

Figure 2: Graphical line representation of Criteria Points

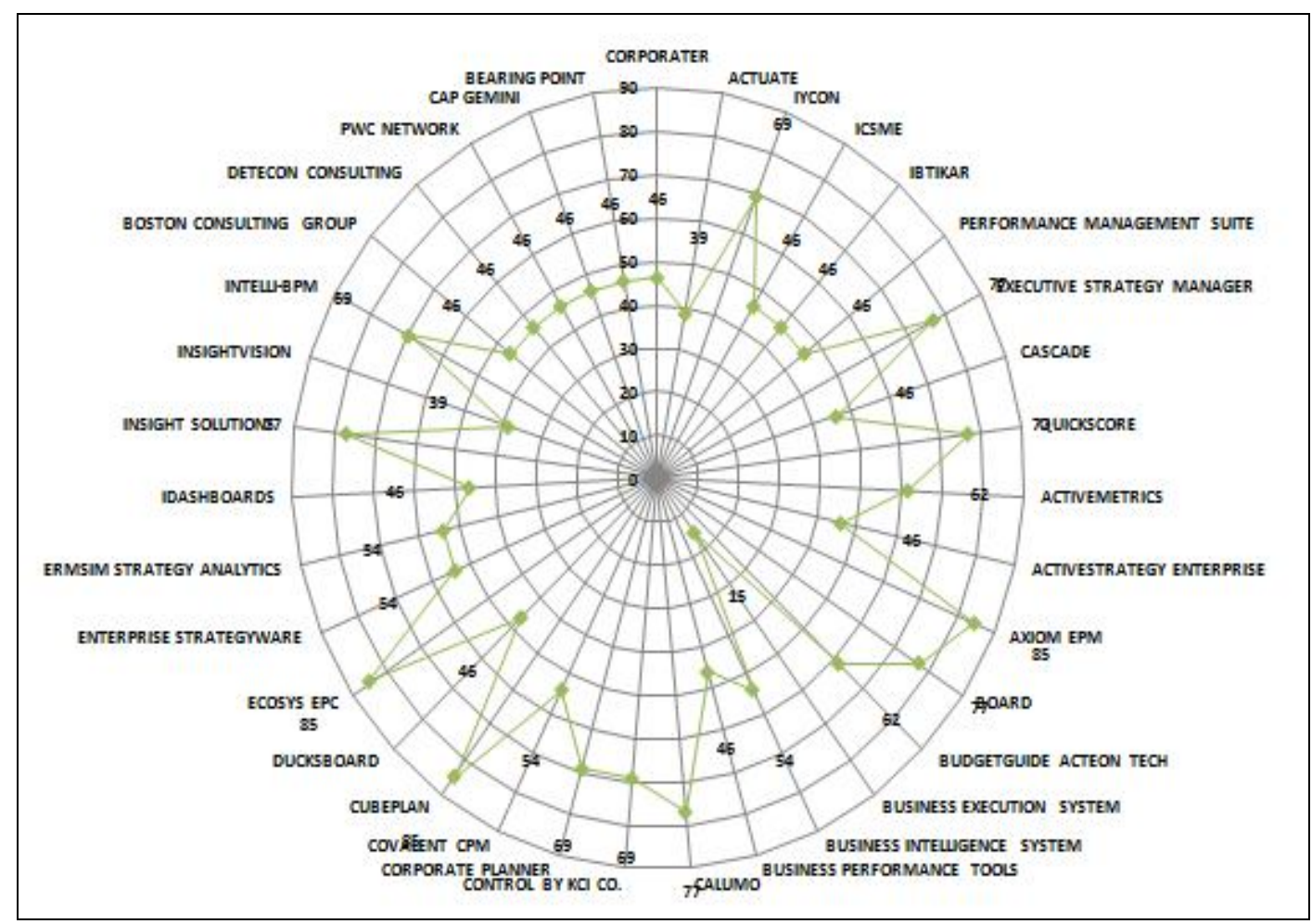

Figure 3: Graphical representation of Criteria Points with companies 


\section{The Criteria for Selecting Strategic Execution Software for Higher Education}

\section{CONCLUSION}

Once the various faculty and department goals and tactics have been aligned with academic strategy and software requirements defined in the selection criteria team can move on to the demo phase with selection evaluation of software suppliers. Product functionality, cost evaluation, technical support technology infrastructure, installation and commissioning processes, field support, and their vision of the future as expressed through their research and development efforts with customer testimonials. These factors are become the key issues of focus while culminating in a selection procedures and decision.

It is obvious that the informed selection of strategic software is a process which is one that is unique to each organizational need, its structure, the capabilities and personalities of its staff's ad executives. Regardless of process methodology, however, this is certain that the odds of choosing the correct software tool will be greatly enhanced if the team's selection process and tactics completely align with the institutional strategic goals and objectives. If your process tactics are sound and strong enough, you will be succeeded, otherwise, your worst nightmare will come true [6].

In this software selection procedure, we have faced lots of difficulties. Sometimes, vendors having no information on their websites, some are not answering on telephone and some vendors are less bothers about our queries. At last, after a rigorous and painstaking struggling, we have selected few best vendors who may provide better product functionalities with adequate infrastructure facilities and technical support with installation and integration for our strategic requirements.

\section{REFERENCES}

[1.] For selection of software, data retrieved on 13 August 2015 from http://www.capterra.com/business-performancemanagement-software/

[2.] Data retrieve on 15 august 2015 from http://www.softwaretestinggenius.com

[3.] http://www.nagarro.com/at/de/blog/post/18/Are-YouSelecting-the-Best-Tools-for-Mobile-Software-Testing(Checklist-)\#sthash.afrCYYiC.dpuf

[4.] The Art of Software Testing - Myers, Glenford J.

[5.] Software Testing \& Continuous Quality Improvement - W E Lewis

[6.] Data retrieved on13 August 2015 from http://www.forteindustries.com/blog/ selecting-enterprise-software-whystrategic-and-tactical-decisions-require-alignment.aspx

[7.] Strategic Planning (2015), retrieved from http://www.webcrawler.com/ info. wbcrwl.305.03/search/web?q=strategic+business+plan ning\&cid $=126727384 \&$ ad. network $=$ s\&ad. $k$ eyword=strategi c\%20business \%20planning\&ad.creative $=23581917664 \&$ ad. position $=1 \mathrm{t} 4 \&$ ad.placement $=\&$ ad. matchtype $=\mathrm{b} \& \mathrm{ad}$. aceid $=$ $\&$ ad.ismobile $=\&$ ad.device $=c \&$ ad.devicemodel $=\&$ ad. segme $\mathrm{nt}=$ info. wbcrwl.305.03\&gclid=CMeBxaHpwccCFWPnwgo dNG8KzA on 10 august 2015.

[8] Performance Management (2015), retrieved the data from http://www.qpr.com/solutions/performancemanagement?gclid=CKW576P wwccCFUI_GwodhrADOA on 10 august 2015 .
[9] Data

retrieved from http://searchcio.techtarget.com/definition/dashboard on 15 August 2015.

[10] Most of the criteria definition retrieved from https://en.wikipedia.org/wiki/ Balanced_scorecard on 15 August 2015. 